\title{
Pensonomonoor
}

2016, vol. 75, 157-165

http://dx.doi.org/10.12657/denbio.075.015

\author{
Haliza Ismail, Sures Kumar Muniandi, Aziah Mohd Yusoff, \\ Nor Hasnida Hassan, Nor Aini Ab Shukor*
}

\section{In Vitro micropropagation of Acacia auriculiformis from selected juvenile sources}

Received: 6 July 2015; Accepted: 29 February 2016

\begin{abstract}
The effects of 6- Benzylaminopurine (BA), different basal medium, sucrose concentration and gelling agent were investigated for shoot induction and multiplication of Acacia auriculiformis. Nodal explants derived from 5-month-old seedlings yielded the highest shoot multiplication rate in Murashige and Skoog medium (MS) with $0.44 \mu \mathrm{M}$ BA, $30 \mathrm{~g} / \mathrm{L}$ sucrose and $2 \mathrm{~g} / \mathrm{L}$ Gelrite. The highest mean number of shoots $(10)$ and mean length of shoots $(5.07 \mathrm{~mm})$ were also obtained in this medium. Qualitative observation of the shoots cultured in $0.44 \mu \mathrm{M}$ BA were greener and vigorous in growth as compared to shoots cultured on higher concentrations of BA $(22.2 \mu \mathrm{M})$. MS medium produced a significantly higher number of shoots (18) compared to Woody Plant Medium (WPM) (11) and B5 medium (10). Media solidified with different gelling agents also produced a significantly different number of shoots with $2 \mathrm{~g} / \mathrm{L}$ Gelrite produced the highest number of shoots (23). The highest percentage of shoots rooted was found in the MS medium without any growth regulators (40.0\%) followed by medium supplemented with Indole-3-butyric acid (IBA) at $9.84 \mu \mathrm{M}$ and the combination of $9.84 \mu \mathrm{M}$ IBA with $5.37 \mu \mathrm{M} \alpha$-naphthalene acetic acid (NAA) $(33.3 \%)$. MS medium without any plant growth regulators produced the highest mean root length $(84.33 \mathrm{~mm})$, whereas medium supplemented with $9.84 \mu \mathrm{M}$ IBA produced the highest mean number of roots per shoot (4.33). Out planting of in vitro rooted shoots in shredded coconut husk as the substrate gave the highest percentage of survival $(90 \%)$ during acclimatization in the greenhouse.
\end{abstract}

Keywords: basal medium, 6-Benzylaminopurine, sucrose, gelling agent, micropropagation, Acacia auriculiformis

Addresses: H. Ismail, Forest Research Institute Malaysia, 52109, Kepong, Selangor, Malaysia

S.M. Kumar, Department of Forest Management, Faculty of Forestry, Universiti Putra Malaysia 43400, Serdang, Selangor, Malaysia.

M.Y. Aziah, University Selangor, Bestari Jaya, Selangor, Malaysia

N.H. Hasnida, Forest Research Institute Malaysia, 52109, Kepong, Selangor, Malaysia

A.S. Nor Aini, Department of Forest Management, Faculty of Forestry, Universiti Putra Malaysia 43400 Serdang, Selangor, Malaysia; Institute of Tropical Forestry and Forest Products, Universiti Putra Malaysia, 43400, Serdang, Selangor, Malaysia, e-mail: anishukor@yahoo.com

*Corresponding author 


\section{Introduction}

Acacia auriculiformis A.Cunn. ex Benth., a native species of Papua New Guinea, Islands of Torres Strait and northern Australia is a fast growing tree species, reaching a height of $30 \mathrm{~m}$ with a trunk diameter up to $60 \mathrm{~cm}$ in natural stands (Phi, 2009; Ismail et al., 2012). This Acacia species is considered to be one of the most promising because of its ability to thrive on a wide range of harsh environmental conditions, such as under poor soil fertility and extended dry periods. It has been introduced as an advanced plantation species for various purposes in countries such as Malaysia, Indonesia, Vietnam, India, West and South Africa as well as South America (Nor Aini et al., 1994; Turnbull et al., 1997; Shukla et al., 2007; Phi, 2009).

Acacia auriculiformis has relatively short fibres about $1.1 \mathrm{~mm}$ in length long and $20.6 \mu \mathrm{m}$ wide, and it has been used as a main plantation tree species for the production of pulp and paper in many countries (Turnbull et al., 1997; Jahan et al., 2008). Acacia auriculiformis is also known for its pharmacological properties notably as an anti-helminthic and for its antifilarial, microbicidal activity (Ghosh et al., 1993; Mandal et al., 2005).This tree species also has potential in the pharmaceutical industry because of its spermicidal and anti-HIV properties along with the safe use on vaginal epithelium (Girijashankar, 2011).

There have been reports that Acacia species including A.auriculiformis have been successfully micropropagated (Mittal et al., 1989; Girijashankar, 2011; Ismail et al., 2012; Banerjee, 2013; Griffin et al., 2014). Most micropropagation techniques for mass propagation of A.auriculiformis have been mainly limited to on juvenile plant material for short-term studies, on establishment of protocols from aseptically germinated seedlings (Ismail et al., 2012; Pijut et al., 2012). The heterozygous nature of the parents and unselected seed sources as plant material is not favorable in any advanced tree improvement program for production of uniform stock with high genetic stability.

Several factors are recognized to have significant effects on micropropagation, the physical and physiological condition of the explant, composition of the culture medium, plant growth regulators, gaseous environment (oxygen and carbon dioxide) and the physical environment (temperature, light and humidity) (George, 1993). One limiting factor of micropropagation for production of planting stock is the high cost. Studies to minimize the cost without sacrificing the quality and quantity of the material are important. In order to achieve the optimum environmental conditions for plant growth, physical factors need to be optimized. These include gelling agent, sucrose concentration, concentration of plant growth regulators, suitable type of basal medium formulation (Hamidah, 1991).

Sucrose has been the carbohydrate chosen most for micropropagation of woody species (Romano et al., 1995). Sucrose is necessary for direct and indirect morphogenesis. To obtain optimum morphogenesis it is therefore important to vary the sucrose content of the medium. Two-to four-percent of sucrose is usually the optimal concentrations for micropropagation. Murashige and Skoog (MS, 1962) reported that $3 \%(\mathrm{w} / \mathrm{v})$ sucrose was better than $2 \%(\mathrm{w} / \mathrm{v})$ and $4 \%(\mathrm{w} / \mathrm{v})$ in tobacco tissue cultures.

Plant organs and tissues are most suitably retained above the surface of a culture medium by increasing its viscosity with various kinds of gelling agent. Various brands and grades of agar or gelling agents are available commercially which differ in the amount of impurities they contain and their gelling capabilities. Both of these characteristics can alter the chemical and physical properties of a medium (George, 1993). The type of agar also affects growth and development (Debergh, 1983). There should be a good medium to plant contact to allow adequate uptake of nutrients. Lower concentrations of gelling agent allow more nutrient uptake and contact, but if the explants sink into the agar, aeration is impaired. Inadequate concentrations of agar either do not support explants or may lead to the induction of hyperhydricity.

Therefore, taking these limiting factors in-to consideration, this work has been developed to evaluate the potential of selected explant to be used as initial plant source for optimization of a micropropagation protocol for A.auriculiformis. The effects of 6- Benzylaminopurine concentrations, basal medium composition, carbon source, and gelling agent on the micropropagation of $A$. auriculiformis were studied and optimized.

\section{Materials and Methods}

\section{Plant Material and Surface Disinfection}

In this study explants were taken from samples of shoots collected randomly from 50 wild seedlings (about 5-month-old) of A auriculiformis growing under selected plus trees at the provenance trial plots in Universiti Putra Malaysia. Shoots were cut approximately to $10 \mathrm{~cm}$ lengths, sealed in plastic bags, and brought back to the laboratory. Field collected samples were soaked in $0.1 \%(\mathrm{w} / \mathrm{v})$ Benlate (fungicide) plus $1 \%$ boric acid and kept in the refrigerator for 24 $\mathrm{h}$ as pretreatment prior to surface disinfection. The nodal explants were surface disinfected in $500 \mathrm{ml}$ of $0.1 \%$ (v/v) mercuric chloride for $10 \mathrm{~min}$, followed by $10 \%$ Chlorox (5.25\% Sodium hypochlorite) for 5 min. Explants were rinsed thoroughly in sterile dis- 
tilled water 3 times following surface disinfection treatment. Strict procedures and safety were practiced when handling mercuric chloride and disposal of waste. Benlate $0.1 \%(\mathrm{w} / \mathrm{v})$ was also incorporated into the initiation medium to reduce contamination. Shoots were then dissected into $1 \mathrm{~cm}$ length nodal segments for culture initiation.

\section{Effects of BA, Basal Medium, Gelling Agent, and Carbon Source on Multiple Shoot Induction}

Five concentrations of BA; $0,0.44,2.22,4.44$, 8.88, $22.2 \mu \mathrm{M}$ in MS medium were used for shoot induction. Three different basal media, Murashige and Skoog meduim (MS) (Murashige \& Skoog, 1962), woody plant medium (WPM) (Lloyd \& McCown, 1981) and Gamborg's B5 medium (Gamborg, 1968), each supplemented with $0.44 \mu \mathrm{M}$ BA were tested. The different gelling agents tested were $2 \mathrm{~g} / \mathrm{L}$ Gelrite (Merck and Co., Rahway, NJ, USA), 10 g/L Difco agar (Difco Laboratories, Detroit, MI, USA), $8 \mathrm{~g} / \mathrm{L}$ Bacto agar (Difco laboratories, Detroit, USA) and $10 \mathrm{~g} / \mathrm{L}$ Vietnam agar (Plain Culture Agar PCA, Laboratory Reagents). MS basal medium was prepared with $0.44 \mu \mathrm{M}$ BA for each of the gelling agents. MS basal medium supplemented with $0.44 \mu \mathrm{M}$ BA, $2 \mathrm{~g} / \mathrm{L}$ Gelrite and 10, 20, 30, or $50 \mathrm{~g} / \mathrm{L}$ sucrose was tested. For each experiment, there were ten replications with 10 shoots per replicate. Initial morphogenesis was assessed weekly, and photographs of the cultures were taken after 4 weeks. Data such as percentage of shoot regeneration, number and length of shoots produced per explant were recorded after 1 month.

\section{Media Preparation and Growth Conditions}

The $\mathrm{pH}$ of the medium was adjusted to 5.8 before dissolving the gelling agent into the medium in microwave. Media was then poured into $30 \mathrm{ml}$ borosilicate test tubes $(20 \times 150 \mathrm{~mm})$ and wrapped with aluminium foil. Tubes were then autoclaved at $121^{\circ} \mathrm{C}$ for $15 \mathrm{~min}$. All plant growth regulators were filter sterilized using a $0.02 \mu \mathrm{m}$ membrane filter and then added to the media under sterile condition after autoclaving. All cultures were maintained under coolwhite fluorescent light with a 16 -h photoperiod at $25^{\circ} \pm 2{ }^{\circ} \mathrm{C}$.

\section{In vitro and ex vitro Rooting of Shoots}

Shoots used for in vitro rooting were approximately $1.5-2 \mathrm{~cm}$, obtained from the sixth cycle of mul- tiplication stage. Treatments used for induction of rooting were MS medium supplemented with either Indole-3-butyric acid (IBA) (0, 0.49, 2.46, 4.92, 9.84 $\mu \mathrm{M})$ or $\alpha$-naphthalene acetic acid (NAA) $(0,0.54$, 2.69, 5.37, $10.74 \mu \mathrm{M})$ and in combination. There were a total of 36 treatments for in vitro rooting experiment. In vitro rooted shoots from $9.84 \mu \mathrm{M}$ IBA were used for acclimatization.

Elongated shoots grown in MS medium supplemented with $0.44 \mu \mathrm{M}$ BA were used for ex vitro rooting. Roots were induced by Seradix 3 (May and Baker Limited, England), a commercial preparation rooting powder containing $0.8 \%(39 \mu \mathrm{M})$ IBA. The elongated shoots approximately $1.5-2 \mathrm{~cm}$ in length were removed from culture tubes and were cut at the basal end to remove the callus-like clump. The basal end of each shoot was wetted with tap water and then applied with Seradix 3. Shoots were then planted into root trainer Plantek 63F (Transplant Systems Ltd, Christchurch, New Zealand). The experiment was conducted with three replications with 10 shoots per replicate. The rooting percentage, number and length of root and axillary root per shoot, shoot length and number of leaves were recorded after 1 month.

\section{Acclimatization of Rooted Shoots}

One-month in vitro rooted shoots were acclimatized in the greenhouse. Three potting media were tested: shredded coconut husk, sand, and a combination of top soil and sand (3:1). The healthy and uniform sized shoots were then selected individually from the test tube and transplanted to polythene bag $(20 \mathrm{~cm} \times 40 \mathrm{~cm})$. Potted shoots were placed in a plastic misting chamber covered with black netting to maintain low temperature and high humidity. The mist sprinkler was set to operate for 1 min every 30 min for $8 \mathrm{~h}$. The temperature was in the range of $25-30^{\circ} \mathrm{C}$ and relative humidity was approximately $80 \%$ with $50 \%$ shade. Ex vitro rooted shoots were acclimatized in the greenhouse with the same potting media and conditions as in the in vitro rooted shoots in misting chamber.

\section{Data Analysis}

All statistical analyses were conducted using Statistical Analysis System Package (SAS) software version 9.3. Data were analyzed for their variances. Further mean separation tests were carried out using the Least Significant Difference (LSD) test. In all data analyses, means differing at a probability of $\leq 0.05$ were considered to be significantly different. 

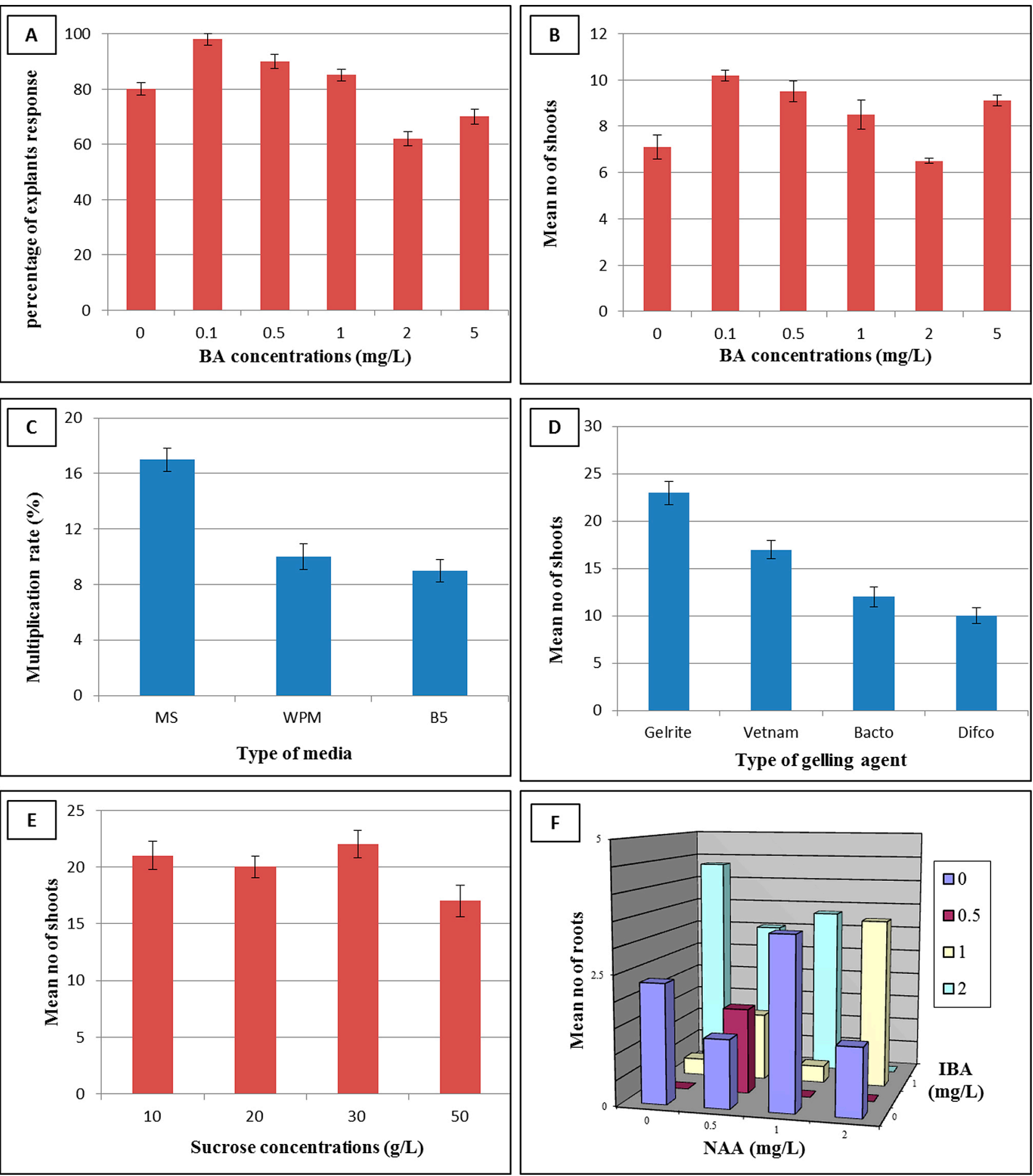

Fig. 1. A) Effect of different concentrations of BA for percentage of shoot regeneration from nodal segments taken from 5-month-old seedlings after 1-month in culture. B) Effect of different concentrations of BA on mean number of shoots produced from nodal segments taken from 5-month-old seedlings after 1-month in culture C) Effect of different basal media on the mean number of shoots from nodal segment explants of 5-month-old seedlings after 6 weeks in culture. D) Effect of different gelling agents on the mean number of shoots from nodal segment explants of 5-month-old seedlings after 6 weeks in culture. E) Effect of different concentrations of sucrose on the mean number of shoots from nodal segment explants of 5-month-old seedlings after 6 weeks in culture. F) Effect of Murashige and Skoog medium supplemented with $\alpha$-naphthalene acetic acid (NAA), Indole-3-butyric acid (IBA), and their combinations on the in vitro rooting of shoots for mean number of roots after 1-month in culture 


\section{Results}

\section{Effects of BA, Basal Media, Gelling Agents, and Sucrose}

There were significant differences at different levels of BA on shoot induction in terms of the percentage of shoot regeneration and the mean number of shoots produced. The highest percentage of shoot regeneration $(100 \%)$ was in MS medium with $0.44 \mu \mathrm{M}$ BA (Fig. 1A), along with the highest mean number of shoots (10) and mean length of shoots (5 $\mathrm{mm}$ ) (Fig. 1B). Qualitative observation of the shoots showed that shoots in $0.44 \mu \mathrm{M}$ BA were greener and more vigorous compared to shoots cultured in higher concentrations of BA such as $22.2 \mu \mathrm{M}$ which were pale green and fragile. Shoots in MS medium without any plant growth regulators were less elongated and did not produce any multiple shoots, but remained healthy.

The mean number of shoots formed in MS medium (18 shoots) was significantly higher compared to B5 medium (10 shoots) and WPM (11 shoots) (Fig. 1C). Shoots in MS medium were also more vigorous in growth and healthier compared to other media (Fig. 2B)

There was a significant difference in the mean number of shoots produced between the media solidified with different gelling agents. Gelrite $(2 \mathrm{~g} / \mathrm{L})$ resulted in the highest number of shoots (23 shoots) compared to other gelling agents (Fig. 1D). Mean number of shoots in Vietnam agar (PCA) (19 shoots) was significantly higher than Bacto-agar (13 shoots) and Difco-agar (11 shoots). Shoots in MS medium solidified with Gelrite and PCA were elongated and vigorous, but the color of shoots in PCA was slightly less green compared to the shoots in Gelrite. Shoots in both Difco and Bacto agars were slow in growth, less elongated and failed to produce multiple shoots (Fig. 2C).

There was no significant difference between different concentrations of sucrose on the mean number of shoots produced (Fig. 1E). However, 50 g/L sucrose produced the lowest number of shoots (18 shoots) compared to shoots in the medium supplemented with $10 \mathrm{~g} / \mathrm{L}$. Shoots in $50 \mathrm{~g} / \mathrm{L}$ sucrose were small and less elongated compared to shoots in other concentrations of sucrose (Fig.2D). Shoots in low concentration of sucrose $(10 \mathrm{~g} / \mathrm{L})$ showed signs of hyperhydricity (vitrification), while there was no vitrification of shoots but browning and defoliation of leaves in higher concentration of sucrose $(50 \mathrm{~g} / \mathrm{L})$.

\section{In Vitro Rooting}

There were significant differences on the percentage of shoots rooted, mean number of roots, mean

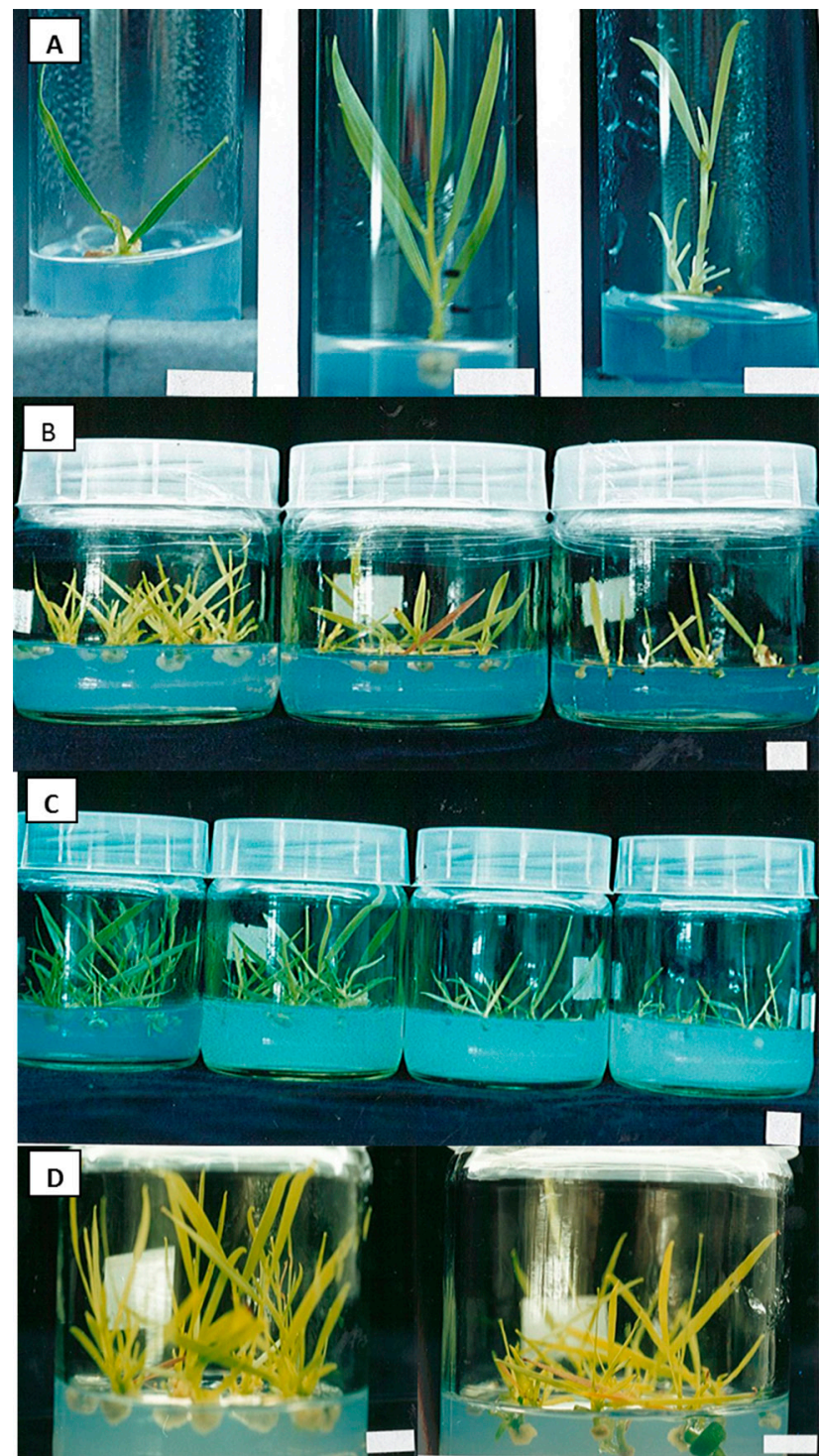

Fig. 2. A) Shoots from explants of 5-month-old seedlings in (left to right): hormone-free MS, $0.44 \mu \mathrm{M}$ BA and $22.22 \mu \mathrm{M}$ BA after a month in culture. B) Shoot multiplication in three different basal media (left to right): MS, WPM and B5 supplemented with $0.44 \mu \mathrm{M}$ after 6 weeks in culture. C) Shoot multiplication in different gelling agents (left to right): Gelrite, Plain Culture Agar (Vietnam Agar), Bacto agar and Difco granulated agar after 6 weeks in culture. D) Shoot multiplication in different sucrose concentrations: $30 \mathrm{~g} / \mathrm{L}$ (left) and $50 \mathrm{~g} / \mathrm{L}$ (right) after 6 weeks in culture. (Note: White bars is equal to $1 \mathrm{~cm}$ )

length of roots, mean number of axillary roots, mean length of axillary roots, and mean height of shoots from the different concentrations of IBA tested. NAA concentration significantly affected the rooting percentage of shoots and mean length of roots. The results showed significant interactions of IBA and NAA in terms of the percentage of shoots rooted, mean number of roots, mean length of roots, mean length of axillary roots and mean height of shoots. There were also significant differences in the percentage of 
Table 1. Analysis of variance on the effects of NAA, IBA and their concentration on the in vitro rooting of shoots from nodal segment explants of 5-month-old seedlings after a month of culture incubation

\begin{tabular}{ccccccccc}
\hline $\begin{array}{c}\text { Source of } \\
\text { variation }\end{array}$ & df & $\begin{array}{c}\text { Percentage of } \\
\text { shoots rooted }\end{array}$ & $\begin{array}{c}\text { Mean no } \\
\text { of root }\end{array}$ & $\begin{array}{c}\text { Mean length } \\
\text { of root }(\mathrm{mm})\end{array}$ & $\begin{array}{c}\text { Mean no of } \\
\text { axillary root }\end{array}$ & $\begin{array}{c}\text { Mean length of } \\
\text { axillary root }(\mathrm{mm})\end{array}$ & $\begin{array}{c}\text { Mean height of } \\
\text { shoots (cm) }\end{array}$ & $\begin{array}{c}\text { \% of explants with } \\
\text { callus at stem bases }\end{array}$ \\
\hline IBA & 3 & $26.00^{*}$ & $10.20^{*}$ & $19.45^{*}$ & $10.27^{*}$ & $3.63^{*}$ & $10.86^{*}$ & $10.66^{*}$ \\
NAA & 3 & $8.81^{*}$ & 1.26 & $3.75^{*}$ & 0.96 & 1.79 & 1.31 & $7.04^{*}$ \\
IBA*NAA & 9 & $10.78^{*}$ & $6.07^{*}$ & $3.29^{*}$ & 1.36 & $3.63^{*}$ & $3.00^{*}$ & $5.44^{*}$ \\
\hline
\end{tabular}

* - significant different at $\mathrm{p} \leq 0.05$.

Table 2. In vitro rooting of Acacia auriculiformis shoots in $\mathrm{Mu}-$ rashige and Skoog medium with $9.84 \mu \mathrm{M}$ Indole-3-butyric-acid in following subculture ( $2^{\text {nd }}$ subculture)

\begin{tabular}{lc}
\hline \multicolumn{1}{c}{ Variable } & Mean \pm Standard Error \\
\hline Percentage of rooted shoots & $70.0 \pm 3.73$ \\
Number of root & $2.1 \pm 0.23$ \\
Length of root & $31.1 \pm 3.75(\mathrm{~mm})$ \\
Number of axillary root & $2.4 \pm 0.50$ \\
Length of axillary root & $3.8 \pm 0.85(\mathrm{~mm})$ \\
Shoot length & $13.1 \pm 0.47(\mathrm{~mm})$ \\
Number of leaves & $2.3 \pm 0.19$ \\
\hline
\end{tabular}

explants forming callus at the stem bases from the different levels of IBA, different levels of NAA and a combination of the two auxins (Table 1).

The highest percentage of shoots rooted $(40 \%)$ was in MS medium without any plant growth regulators followed by shoots rooted in MS medium with 9.84 $\mu \mathrm{M}$ IBA $(33.3 \%)$ and $9.84 \mu \mathrm{M}$ IBA combined with $5.37 \mu \mathrm{M}$ NAA (33.3\%). However, shoots rooted in the following subcultures for acclimatization experiment exhibited higher percentage of rooting (70.0\%) in $9.84 \mu \mathrm{M}$ IBA (Table 2). No rooted shoots were observed in $2.46 \mu \mathrm{M}$ IBA alone or in combination with either $5.37 \mu \mathrm{M}$ or $10.74 \mu \mathrm{M}$ NAA. For the mean number of roots per shoot, the highest was observed in $9.84 \mu \mathrm{M}$ IBA (4.3). The highest mean length of roots was in MS medium without any plant growth regulators $(84.3 \mathrm{~mm})$. The highest mean number of axillary roots was in $5.37 \mu \mathrm{M}$ NAA (9) while the highest mean length of axillary roots was in $4.92 \mu \mathrm{M}$ IBA combined with $10.74 \mu \mathrm{M}$ NAA
$(11 \mathrm{~mm})$. The highest mean height of shoots was in $10.74 \mu \mathrm{M}$ NAA.

\section{Acclimatization and ex vitro Rooting}

Shredded coconut husk as a potting medium gave the highest percentage of survival (90\%) (Table 3). Soil as a potting medium gave the lowest percentage of survival both for ex vitro $(30 \%)$ and in vitro $(25 \%)$ rooted shoots. ANOVA on ex vitro rooting showed that there were significant differences between different potting media on the percentage of shoots surviving (Table 4). Shredded coconut husk gave the highest percentage of survival $(83.3 \%)$ for ex vitro rooted shoots. Low percentages $(6.7 \%$ to $10 \%)$ of shoots rooted ex vitro in all potting media tested (sand, coconut husk and 3:1 top soil: sand).

\section{Discussion}

Three different basal media were tested in this study because most reports on micropropagation of Acacia have used either MS medium (Skolmen \& Mapes, 1976; Yang et al., 1989; Semsuntud \& Nitiwattanachai, 1991), B5 medium (Mittal et al., 1989; Dewan et al., 1992), or WPM and MS medium (Singh et al., 1993). Comparison between the different basal media showed that shoots of A.auriculiformis from 5-month-old seedlings grew better with the highest mean number of shoots in MS medium (18.3) followed by WPM (11.3), and the lowest in

Table 3. The LSD test on the effects of different potting medium on in vitro rooted shoots of Acacia auriculiformis after a month of acclimatization

\begin{tabular}{lcccc}
\hline \multicolumn{1}{c}{ Potting medium } & Shoot survived (\%) & Rooted shoots (\%) & Mean shoot height $(\mathrm{cm})$ & Mean no of leaves \\
\hline Sand & $65.00 \mathrm{~b}$ & $60.00 \mathrm{a}$ & $1.36 \mathrm{a}$ & $2.90 \mathrm{a}$ \\
Soil: Sand & $25.00 \mathrm{c}$ & $12.35 \mathrm{c}$ & $1.37 \mathrm{a}$ & $2.80 \mathrm{a}$ \\
Coconut Husk & $90.00 \mathrm{a}$ & $86.66 \mathrm{~b}$ & $1.41 \mathrm{a}$ & $2.65 \mathrm{a}$ \\
\hline
\end{tabular}

Values having the same lettering were not significantly different.

Table 4. The LSD test on the effects of different potting medium on the ex vitro rooting of Acacia auriculiformis shoots after month of acclimatization

\begin{tabular}{|c|c|c|c|c|}
\hline Potting medium & Shoot survived (\%) & Rooted shoots (\%) & Mean shoot height $(\mathrm{cm})$ & Mean no of leaves \\
\hline Sand & $73.33 a$ & $10.00 \mathrm{a}$ & $1.72 \mathrm{a}$ & $3.57 \mathrm{a}$ \\
\hline Soil: sand & $30.00 \mathrm{~b}$ & $6.67 a$ & $1.55 \mathrm{a}$ & $3.43 a$ \\
\hline Coconut Husk & $83.33 a$ & $6.67 a$ & $1.48 \mathrm{a}$ & $3.10 \mathrm{a}$ \\
\hline
\end{tabular}

Values having the same lettering were not significantly different. 
B5 medium (10). This is concurrent with what has been reported by Singh et al. (1993) who found that bud breaks were more and faster in MS medium (90.8\%) compared with WPM (88.4\%), B5 medium $(70.2 \%)$, White medium (33.0\%), and Schenk and Hildebrandt (SH) medium (45.0\%) for shoot initiation of $A$. nilotica. MS medium has also been used in most work on micropropagation of Acacia species (Mathur \& Chandra, 1983; Crawford \& Hartney, 1987; Basri et al., 1989; Jones et al., 1990; Darus, 1991a; Galiana et al., 1991; Badji et al., 1993; Puri \& Jain, 1995; Nangia \& Singh, 1996; Ismail et al., 2012; Griffin et al., 2014). In some cases, half-strength MS medium in which major non-organic elements were reduced by half was more suitable for in vitro propagation of some leguminose tree species. Yuji et al. (1993) found that one-month-old aseptically germinated seedlings of $A$. auriculiformis performed better in terms of growth and shooting in half-strength MS medium. Similarly, Badji et al. (1993) also reported optimization of in vitro growth conditions using halfstrength MS medium in micropropagation of 4-yearold and one-month-old aseptically germinated seedlings of A.senegal.

Experiment conducted on the shooting variation due to cytokinin BA concentration revealed that low concentration of BA $(0.44$ or $2.22 \mu \mathrm{M})$ were sufficient for shoot initiation in terms of the mean number of shoots and shoot elongation for 5-month-old explants. According to Darus (1991b) and Galiana et al. (1991), low level of BA $(2.22 \mu \mathrm{M})$ was good for shoot multiplication and elongation of A.mangium. The same concentration was also found to be favorable for maximum shoot multiplication and elongation of Acacia hybrid (Darus, 1991a). Similarly, in the case of A.nilotica, low levels of BA (1.1 to $8.88 \mu \mathrm{M})$ either with or without kinetin or $2 \mathrm{ip}$ have been reported to induce axillary bud development (Singh et al., 1993). Higher rates of cytokinin have caused production of many small shoots which typically fail to elongate and/or induce shoots to become hyperhydric (George, 1993). For instance, in this study, shoots produced in higher concentration of BA $(22.22 \mu \mathrm{M})$ exhibited characteristics of pale green, less vigorous shoots with small stunted shoots at the base.

In this study, different concentrations of sucrose ranging from 10 to $50 \mathrm{~g} / \mathrm{L}$ had no significant effect on the multiplication of shoots in terms of the mean number of shoots produced. However, the shoots cultured in $10 \mathrm{~g} / \mathrm{L}$ sucrose showed signs of hyperhydricity. Hyperhydricity or vitrification is the term generally used to characterize the hyperhydric malformations frequently affecting herbaceous and woody plants. The so-called vitrified or vitreous plants appear turgid or hyperhydric, watery at their surface, and hypolignified. Their tissues were somewhat translucent, in some cases less green, and were easily breakable (Jones, 1976; Werner \& Boe, 1980). Romano et al. (1995), found $30 \mathrm{~g} / \mathrm{L}$ sucrose was the best carbon source for proliferation of Quercus robur (English Oak) which favored shoot elongation. In this study, the quality of $A$. auriculiformis shoots was observed to be good in 20 to $30 \mathrm{~g} / \mathrm{L}$ sucrose. The $A$. auriculiformis shoots produced in $50 \mathrm{~g} / \mathrm{L}$ sucrose were less elongated compared to others and had the lowest number of shoots per explant. This effect might be a result of due to the carbohydrate concentration (sucrose) modifying the osmotic strength of the medium (Thompson \& Thorpe, 1987). At a high osmotic strength the medium was shown to reduce plant height and slow growth (Short et al., 1987). Maretzki et al. (1972) also found that when the concentration of sucrose in a high salt medium such as MS medium was increased above $4-5 \%(40-50 \mathrm{~g} / \mathrm{L})$, there would be a progressive inhibition of cell growth in many types of cultures. This appears to be an osmotic effect because addition of other osmotically-active substances (such as mannitol and polyethylene glycol) to the medium also caused similar responses.

Nairn (1993) reported that among all media components used, gelling agents have exerted the most powerful controlling influence on successful micropropagation of Pinus radiata. In this study, $2 \mathrm{~g} / \mathrm{L} \mathrm{Gel-}$ rite was found to be the most suitable for shoot multiplication. Compared to other types tested (Plain culture agar (PCA), Difco Bacto, and Difco granulated agar), A. auriculiformis produced vigorous shoot growth with Gelrite. Mean number of shoots was not significantly different between Gelrite and PCA, but the shoots were slightly chlorotic in PCA. According to George and Sherrington (1984), gelling agent that can promote good growth of cultures with low cost is more profitable for commercial practices. In this case, PCA at present was the cheapest gelling agent compared to others. Incorporating both Gelrite and PCA in certain proportions into the medium might produce optimal shoot multiplication with good quality shoots.

For ex vitro rooting, shredded coconut husk was better than other types of potting medium in terms of the percentage of plantlet survival. Although the percentage of shoots rooted ex vitro was quite low (6.7\% in shredded coconut husk), the percentage of survival after 1-month was high (83.3\%). A high percentage of survival was also achieved for in vitro rooted shoots (90\%). The high percentage of survival obtained in coconut husk might be a result of the better water retention and drainage provided by the coconut husk. Fine sand or vermiculite was used by Semsuntud and Nitiwattanachai (1991) for ex vitro rooting of $A$.auriculiformis where $38 \%$ of shoots rooted after 3 months. However, in this study, river sand which was used in ex vitro rooting produced only $10 \%$ rooted shoots rooted after 1-month. As a conclusion, 
the techniques described in this study are highly reproducible and efficient, and these can be utilized to mass propagate selected clones with desirable attributes of $A$. auriculiformis.

\section{Acknowledgement}

We thank all staff members of the Tissue Culture Laboratory and Forest Biotechnology Division, Forest Research Institute Malaysia for their help and support.

\section{References}

Badji S, Mairone Y, Ndiaye I, Merlin G, Danthu P \& Neville P (1993) In vitro propagation of the gum arabic tree (Acacia senegal (L.) Willd.). 1. Developing a rapid method for producing plants. Plant Cell Reports 12: 629-633.

Banerjee P (2013) Rapid in vitro propagation of Acacia auriculiformis on solid and liquid media: role of organic additive, antioxidant and plant growth regulators. Cibtech Journal of Bio-Protocols 2: 39-49.

Basri H, Christine ZA \& Jamari S (1989) In vitro propagation of Acacia mangium from young seedlings: Proceeding of the seminar on the tissue culture of forest species (ed. by AN Rao \& MY Aziah) pp. 129-132.

Crawford DF \& Hartney VJ (1987) Micropropagation of Acacia mangium and Acacia stenophylla: Australian Acacias in Developing Countries. Proceedings of an International Workshop held at the Forestry Training Centre, Gympie, Qld., Australia, and 4-7 August 1986 (ed. by JW Turnbull) ACIAR Proceeding No. 16: 64-65.

Darus HA (1991a) Micropropagation techniques for Acacia mangium $\times$ Acacia auriculiformis: Breeding technologies for tropical Acacias. Proceedings of an International Workshop held in Tawau, Sabah, Malaysia, 1-4 July 1991 (ed. by LT Carron \& KM Aken) ACIAR Proceedings No. 37: 119-121.

Darus HA (1991b) Micropropagation of Acacia mangium from aseptically germinated seedlings. Journal of Tropical Forestry Sciences 3: 204-208.

Debergh PC (1983) Effects of agar brand and concentration on tissue culture medium. Physiologia Plantarum 59: 270-276.

Dewan A, Nanda K \& Gupta SC (1992) In vitro micropropagation of Acacia nilotica subsp. Indica Brenan via cotyledonary nodes. Plant Cell Reports 12: 18-21.

Galiana A, Tibok A \& Duhoux E (1991) In vitro propagation of the nitrogen-fixing tree-legume Acacia mangium Willd. Plant and Soil 135: 151-159.
Gamborg OL, Miller RA \& Ojima K (1968) Nutrient requirements of suspension cultures of soybean root cells. Experiment Cell Research 50: 151-158.

George EF (1993) Plant propagation by tissue culture. Part I - The technology. Exegetics Ltd., Edington, England.

George EF \& Sherrington PD (1984) Plant propagation by tissue culture. Handbook and directory of commercial laboratories. Exegetics Limited, Eversley, Baringstoke.

Ghosh M, Babu SP, Sukul NC \& Mahato SB (1993) Antifilarial effect of two triterpenoid saponins isolated from Acacia auriculiformis. Indian Journal of Experimental Biology 31: 604-606.

Girijashankar V (2011) Micropropagation of multipurpose medicinal tree Acacia auriculiformis. Journal of Medicinal Plant Research 5: 462-466.

Griffin A, Kumar SM \& Nor Aini AS (2014) In vitro regeneration of Acacia crassicarpa A. Cunn Ex Benth through organogenesis from juvenile sources. Journal of Food, Agriculture and Environment 12: 375-382.

Hamidah M (1991) Mikroperambatan dan kesan sinaran keatas Chrysanthemum morifolium Ramat.var. Gerth. Master's Thesis, Universiti Kebangsaan Malaysia.

Ismail H, Nor Aini AS, Aziah MY, Nor HH, Fadhilah Z, Nazirah A \& Siti SAR (2012) In vitro shoot induction of Acacia auriculiformis from juvenile and mature sources. Journal of Biotechnology and Pharmaceutical Research 3: 88-93.

Jahan MS, Sabina R \& Rubaiyat A (2008) Alkaline pulping and bleaching of Acacia auriculiformis grown in Bangladesh. Turkish Journal of Agriculture and Forestry 32: 339-347.

Jones OP (1976) Effect of phloridzin and phloroglucinol on apple shoots. Nature 262: 392-393.

Jones TC, Batchelor CA \& Harris PJC (1990) In vitro culture and propagation of Acacia species (A. bivenosa, A.holosericea, A.salicina, A.saligna and A.sclerosperma). International Tree Crops Journal 6: 183-192.

Lloyd G \& McCown B (1981) Commercially-feasible micropropagation of Mountain Laurel, Kalmia latifolia, by use of shoot tip culture. Combined Proceedings - International Plant Propagator's Society 30: 421-427.

Mandal P, Babu SPS \& Mandal NC (2005) Antimicrobial activity of saponins from Acacia auriculiformis. Fitoterapia 76: 462-465.

Maretzki A, Thom A \& Nickell LG (1972) Influence of osmotic potentials on the growth and chemical composition of sugarcane cell cultures. Hawaii Plant Research 58: 183-199.

Mathur I \& Chandra N (1983) Induced regeneration in stem explants of Acacia nilotica. Current Science 52: $882-883$. 
Mittal A, Agarwal R \& Gupta SC (1989) In vitro development of plantlets from axillary buds of Acacia auriculiformis - a leguminous tree. Plant Cell, Tissue and Organ Culture 19: 65-70.

Murashige T \& Skoog F (1962) A revised medium for rapid growth and bio assays with tobacco tissue cultures. Physiologia Plantarum 15: 473-497.

Nairn B (1993) Commercial micropropagation of Radiata pine: Micropropagation of Woody Plants (ed. by MR Ahuja) Kluwer Academic Publishers, The Netherlands.

Nangia S \& Singh R (1996) Micropropagation of Acacia tortilis Hayne (umbrella thorn) through cotyledonary node culture. Indian Journal of Plant Physiology 1: 77-79.

Nor Aini AS, Kamis A, Mansor MR \& Senin AL (1994) Provenance trial of Acacia auriculiformis in Peninsular Malaysia: 12-month performance. Journal of Tropical Forest Science 6: 249 -256.

Phi HH (2009) Genetic improvement of plantation grown Acacia auriculiformis for sawn timber production. Doctoral Thesis, Swedish University of Agricultural Sciences.

Pijut PM, Beasley RR, Lawson SS, Palla KJ, Stevens ME \& Wang Y (2012) In vitro propagation of tropical hardwood tree species-A review (2001-2011). Propagation of Ornamental Plants 12: 25-51.

Puri S \& Jain M (1995) Callus induction in explants of Acacia catechu. Nitrogen Fixing Tree Research Reports 13: 19-22.

Romano A, Noronha C \& Martins-Loucao MA (1995) Role of carbohydrates in micropropagation of cork oak. Plant Cell, Tissue and Organ Culture 40: 159-167.

Semsuntud N \& Nitiwattanachai W (1991) Tissue culture of Acacia auriculiformis: Advances in Tropical Acacia Research. Proceeding of an International Workshop held in Bangkok, Thailand, 11-15 February, 1991 (ed. by JW Turnbull). ACIAR Proc. No. 35: 39-42.
Short KC, Warburton J \& Robert A (1987) In vitro hardening of cultured cauliflower and chrysanthemum plantlets to humidity. Acta Horticulture 212: 329-334.

Shukla SR, Rao RV, Sharma SK, Kumar P, Sudheendra R \& Shashikala S (2007) Physical and mechanical properties of plantation-grown Acacia auriculiformis of three different ages. Australian Forestry 70: 86-92.

Singh HP, Singh S, Saxena RP \& Singh RK (1993) In vitro bud break in axillary nodal segments of mature trees of Acacia nilotica. Indian Journal of Plant Physiology 36: 21- 24.

Skolmen RG \& Mapes MO (1976) Acacia koa Gray plantlets from somatic callus tissue. The Journal of Heredity 67: $114-115$.

Thompson M \& Thorpe T (1987) Metabolic and non-metabolic roles of carbohydrates: Cell and Tissue Culture in Forestry (ed. by JM Bonga \& DJ Durzan) Martinus Nijhoff Publishers, Dordrecht, Netherlands.

Turnbull JW, Midgley SJ \& Cossalter C (1997) Tropical Acacias planted in Asia: an overview of recent developments in Acacias planting: Proceedings of recent developments in Acacia planting (ed. by JW Turnbull) Hanooi, Vietnam pp. 14-18.

Werner EM \& Boe AA (1980) In vitro propagation of Malling-7 apple rootstocks. Hortscience 15: 509 -510 .

Yang JC, Lu MC, Tsay JY \& Ho CK (1989) In vitro culture of Acacia auriculiformis, A.mangium and their interspecific hybrids: Proceedings of the Sixth International Congress of SABRAO, Malaysia, pp. 865-868.

Yuji I, Yoshihiro W, Yoko S, Katsumi K \& Satohiko S (1993) Establishment of tissue and cell culture system of tropical Acacia species for acid-resistant clones: Proceedings of International Workshop BIO-REFOR, Yogyakarta, pp. 149-153. 